BMJ Open

Diabetes

Research

\& Care

\title{
Feasibility study of real-time online text- based CBT to support self-management for people with type 1 diabetes: the Diabetes On-line Therapy (DOT) Study
}

Anne M Doherty (1) , ${ }^{1,2}$ Anne Herrmann-Werner, ${ }^{3}$ Arann Rowe, ${ }^{4}$ Jennie Brown, ${ }^{5}$ Scott Weich, ${ }^{6}$ Khalida Ismail ${ }^{7}$

To cite: Doherty AM, Herrmann-Werner A, Rowe A, et al. Feasibility study of realtime online text-based CBT to support self-management for people with type 1 diabetes: the Diabetes Online Therapy (D0T) Study. BMJ Open Diab Res Care 2021;9:e001934. doi:10.1136/ bmjdrc-2020-001934

Received 2 October 2020 Revised 2 December 2020 Accepted 20 December 2020

Check for updates

\section{(C) Author(s) (or their} employer(s)) 2021. Re-use permitted under CC BY-NC. No commercial re-use. See rights and permissions. Published by BMJ.

For numbered affiliations see end of article.

Correspondence to Dr Anne M Doherty; anne.doherty@ucd.ie

\section{ABSTRACT}

Introduction This study examines the feasibility of conducting diabetes-focused cognitive-behavioral therapy (CBT) via a secure online real-time instant messaging system intervention to support selfmanagement and improve glycemic control in people with type 1 diabetes.

Research design and methods We used a pre-post uncontrolled intervention design over 12 months. We recruited adults with type 1 diabetes and suboptimal glycemic control (HbA1c $\geq 69 \mathrm{mmol} / \mathrm{mol}$ (DCCT 8.5\%) for 12 months) across four hospitals in London. The intervention comprised 10 sessions of diabetes-focused CBT delivered by diabetes specialist nurses. The primary outcomes were number of eligible patients, rates of recruitment and follow-up, number of sessions completed and SD of the main outcome measure, change in $\mathrm{HbA1C}$ over 12 months. We measured the feasibility of collecting secondary outcomes, that is, depression measured using Patient Health Questionnaire-9 (PHQ-9), anxiety measured Generalised Anxiety Disorder (GAD) and the Diabetes Distress Scale (DDS).

Results We screened 3177 patients, of whom 638 were potentially eligible, from whom 71 (11.1\%) were recruited. The mean age was 28.1 (13.1) years, and the mean $\mathrm{HbA} 1 \mathrm{C}$ was $84.6 \mathrm{mmol} / \mathrm{mol}$ (17.8), DCCT 9.9\%. Forty-six (65\%) patients had at least 1 session and $29(41 \%)$ completed all sessions. There was a significant reduction in $\mathrm{HbA} 1 \mathrm{C}$ over 12 months (mean difference $-6.2(2.3) \mathrm{mmol} / \mathrm{mol}, \mathrm{DCCT}$ $0.6 \%, p=0.038$ ). The change scores in PHQ-9, GAD and DDS also improved.

Conclusions It would be feasible to conduct a full-scale text-based synchronized real-time diabetes-focused CBT as an efficacy randomized controlled trial.

\section{INTRODUCTION}

Around half of patients with type 1 diabetes do not achieve effective levels of glycemic control as recommended in National Institute for Health and Care Excellence guidance (UK standards) ${ }^{1}$ despite the widespread access to interventions such as structured education and diabetes technologies which have an evidence base for improving

\section{Significance of this study}

What is already known about this subject?

- Around half of patients with type 1 diabetes do not achieve effective levels of glycemic control, and there is growing evidence of the efficacy of psychological treatments in improving glycemic control in type 1 diabetes, but it remains unclear whether diabetes-focused cognitive-behavioral therapy (CBT) in the virtual setting can also lead to improved glycemic control.

What are the new findings?

- Online CBT for type 1 diabetes mellitus (T1DM) is an acceptable and feasible intervention for certain patients: in the context of COVID-19, it is very important to have access to effective treatments which may be delivered remotely.

- In those patients who are able to engage with the therapy, significant improvement in glycemic control was reported: mean $(S D)=6.2(2.3) \mathrm{mmol} / \mathrm{mol}$.

- This suggests that this may be an important adjuvant treatment in the management of complex T1DM where glycemic control is suboptimal and may reduce the risk of developing complications of diabetes.

- There were trend improvements in symptoms of anxiety, depression or diabetes-related distress among participants who had elevated scores in measures of these symptoms at baseline.

How might these results change the focus of research or clinical practice?

- This provides evidence that a virtual approach to the delivery of diabetes-focused CBT may be successful in empowering patients to optimize their diabetes management and improve their glycemic control, reducing their risk of developing diabetes complications.

HbAlc. ${ }^{2-4}$ One possible reason is that living with type 1 diabetes is associated with significant psychological distress, the most common being depressive symptoms, anxiety and 
diabetes-specific distress, which is associated with difficulties in optimizing diabetes self-management, persistent hyperglycemia and higher risk of earlier onset of diabetes complications and premature mortality. ${ }^{5-9}$ Some patients experience stigma around their diabetes and changes in lifestyles, and these can accentuate this psychological distress. $^{1011}$

There is growing evidence of the efficacy of psychological treatments in improving glycemic control in type 1 diabetes. ${ }^{12}$ A multi-center randomized controlled trial (RCT) demonstrated that nurse-led motivational interviewing combined with basic cognitive-behavioral therapy (CBT) skills was more effective than usual care in improving glycemic control (mean difference in reduction in $\mathrm{HbAlc}=5.5 \mathrm{mmol} / \mathrm{mol}$ ) in 340 adults with type 1 diabetes and persistent suboptimal glycemic control. ${ }^{13} 14$ However, it was not more cost-effective. ${ }^{15}$ One reason may be that the intervention was limited to patients who could attend face-to-face sessions in the participating hospitals. Patients on average completed $50 \%$ of the sessions and said that attending for mental health separate to diabetes care was time consuming, costly and burdensome. ${ }^{16}$

Psychological treatments using internet-based instant messaging systems offer an alternative to face-to-face therapy. In routine clinical practice, diabetes health professionals use the internet to access blood glucose (BG) data and give emotional and practical support via email and mobile texts and use mobile phone applications to support patients in carbohydrate counting and calculating insulin doses. There is evidence that these and other forms of telemedicine are effective in improving glycemic control, ${ }^{17}$ and that many patients prefer remote or virtual support to conventional therapy. ${ }^{18}{ }^{19}$ Similarly, among patients with depression, an RCT of CBT delivered using a real-time online instant messaging system was more effective in improving depression scores than usual care.$^{20}$ In patients with depression and type 1 diabetes, an RCT of online CBT focusing on depression reported significant improvement in depressive symptoms, but not in glycemic control. ${ }^{21}$ It appears therefore that where the primary focus of CBT is on diabetes self-management, it is more likely to lead to improved glycemic control in the face-to-face setting. However, it remains unclear whether CBT focusing on diabetes in the virtual setting can also lead to improved glycemic control.

The overall aim of this study was to test the feasibility of an online diabetes-focused CBT-based intervention in type 1 diabetes delivered by diabetes specialist nurses (DSNs). Specifically, we studied the following markers of feasibility: size of study population that was eligible, participation rates, uptake of sessions, and follow-up rates at 6 and 12 months.

\section{MATERIALS AND METHODS Participants}

The target population was people with type 1 diabetes who have persistent hyperglycemia. The study inclusion criteria were adults patients aged $\geq 18$ years with a diagnosis of type 1 diabetes based on hospital records, persistent hyperglycemia $(\mathrm{HbAlc} \geq 69 \mathrm{mmol} / \mathrm{mol}$ on at least two occasions for the past 12 months including the current status) and fluent in conversational English.

The exclusion criteria were those who had no access to the internet; required acute inpatient care for diabetes or unrelated medical conditions at recruitment; had a severe mental illness such psychotic disorder, substance dependence and learning difficulties; had major changes in insulin management (such as change in type of insulin or method of administration) or addition of oral diabetes medication in preceding 3 months; and were pregnant or planning pregnancy.

\section{Design}

This is a pre-post uncontrolled intervention study of a synchronic real-time online diabetes-focused CBT intervention for people with type 1 diabetes over 12 months.

\section{Setting}

We screened the type 1 diabetes electronic databases in four secondary care diabetes clinics in the south east Thames region, UK: King's College Hospital and Guy's and St Thomas's Hospital NHS Foundation Trusts and University Hospital Lewisham and Darent Valley Hospital, which combined serve a diverse socioeconomic and ethnic population of about 0.5 million residents. ${ }^{22}$

\section{Measures}

At baseline, we measured HbAlc $(\mathrm{mmol} / \mathrm{mol})$, duration of diabetes (years), and presence of macrovascular and microvascular diabetes complications using medical records. HbA1c was measured at 6 months and 12 months following recruitment as part of routine care.

We also measured three psychological constructs. We measured depressive symptoms using the Patient Health Questionnaire (PHQ-9), ${ }^{23}$ a 9-item self-report questionnaire (range 0 to 27 ) with a score $\geq 10$ having a high specificity and sensitivity for depressive disorder. To assess symptoms of anxiety, we used the Generalised Anxiety Disorder 7-item scale (GAD-7), ${ }^{24}$ a 7-item self-report questionnaire (range 0-21) with two cut-offs: score $\geq 5$ and score $\geq 10$ for subthreshold and threshold anxiety disorder, respectively. ${ }^{25-27}$ Diabetes-specific distress was measured using the Diabetes Distress Scale (DDS), ${ }^{28}$ a 17-item self-report questionnaire based on four distressrelated domains (emotional burden, physician-related distress, regimen-related distress and diabetes-related interpersonal distress) (range 17-51) and score of $\geq 40$ indicating clinically significant diabetes distress. ${ }^{29}$

\section{Intervention}

The intervention was titled Diabetes Online Therapy (DOT). It was delivered via a real-time instant messaging system using real-time text communication over the internet, accessible by phone or computer on the internet-based platform. A date and time were agreed for each session, at which the patient and therapist met 
and conversed by typing in real time onto a shared platform for the duration of the therapy session (private and secure internet chat room). Each session lasted $50 \mathrm{~min}$. It is an NHS "Connecting for Health" registered platform and thus fulfills NHS security and governance rules protecting patient confidentiality. The electronic platform was provided by a commercial company that provides internet CBT for depression and anxiety commissioned by the NHS in parts of England. ${ }^{30}$ The DOT platform had functions to set up appointments, automatic transcription of the session which can be shared by patient and therapist for secure communication outside sessions, chart progress using disease-specific measures, and to hold online and downloadable materials for guided selfhelp. At the end of each session, the therapist completed a brief summary outlining the main points of the session, along with the CBT homework agreed.

Participants were offered 10 sessions of CBT delivered over 3 months plus two follow-up sessions at monthly intervals. The therapy was delivered by five DSNs who received training in the basics of CBT from a consultant liaison psychiatrist qualified with a postgraduate diploma in CBT over 3 days, with subsequent role play sessions followed by feedback, and weekly supervision from a clinical psychologist trained in CBT over 6 months. We developed a diabetes CBT manual (available on request from authors) which was adapted and refined from an evidence-based face-to-face diabetes CBT manual. ${ }^{16}$ This formed the basis of self-directed learning and served to standardize the delivery of therapy across the nursetherapists. The basic techniques that were taught included eliciting negative diabetes cognitions, basic 3-systems formulation, goal setting, agenda setting and feedback, activity scheduling, behavioral goals and experiments. The therapy was delivered by text, over the internet in real-time in 50 min sessions. While the DSN gave general advice about the management of type 1 diabetes, the specific diabetes care remained the responsibility of the local diabetes team to maintain patient safety.

\section{Ethics}

Informed consent by telephone was obtained from all participants, and a hard-copy signed consent was sent and received by mail.

\section{Statistical analyses}

All statistical analyses were performed using SPSS V.21.0. ${ }^{31}$ We reported baseline characteristics as mean and SD for continuous variables, and as proportions and percentages for categorical variables. We examined the changes in glycemic control within an individual from baseline to 6 months, and from baseline to 12 months using Student paired t-test. We conducted multivariate analysis with change in $\mathrm{HbAlc}$ as the dependent variable, controlling for confounding factors, including age, gender and duration of diabetes. We examined change in the psychological measures from baseline to 12 months. A significance level of 5\% was used throughout. A proxy marker for fidelity to the intervention was derived from the number of sessions attended and categorized into those who did not attend their first session, those who attended at least 1 or 2 sessions, and those who attended all 10 CBT sessions.

\section{RESULTS}

There were $n=3177$ patients on the clinical registers of the four participating hospitals. From this list, we identified $n=638$ patients who were potentially eligible because they met the inclusion criterion of at least $1 \mathrm{HbAlc} \geq$ $69 \mathrm{mmol} / \mathrm{mol}$ in the past 12 months who were invited in writing by their clinician for further screening and consent. Of these, $\mathrm{n}=90$ patients replied and $\mathrm{n}=71(79 \%)$ consented to participate (figure 1). The majority were female and of White ethnicity, mean age was 28.1 (13.1) years and over half had a university degree. Mean duration of type 1 diabetes was 18.3 (10.3) years and mean

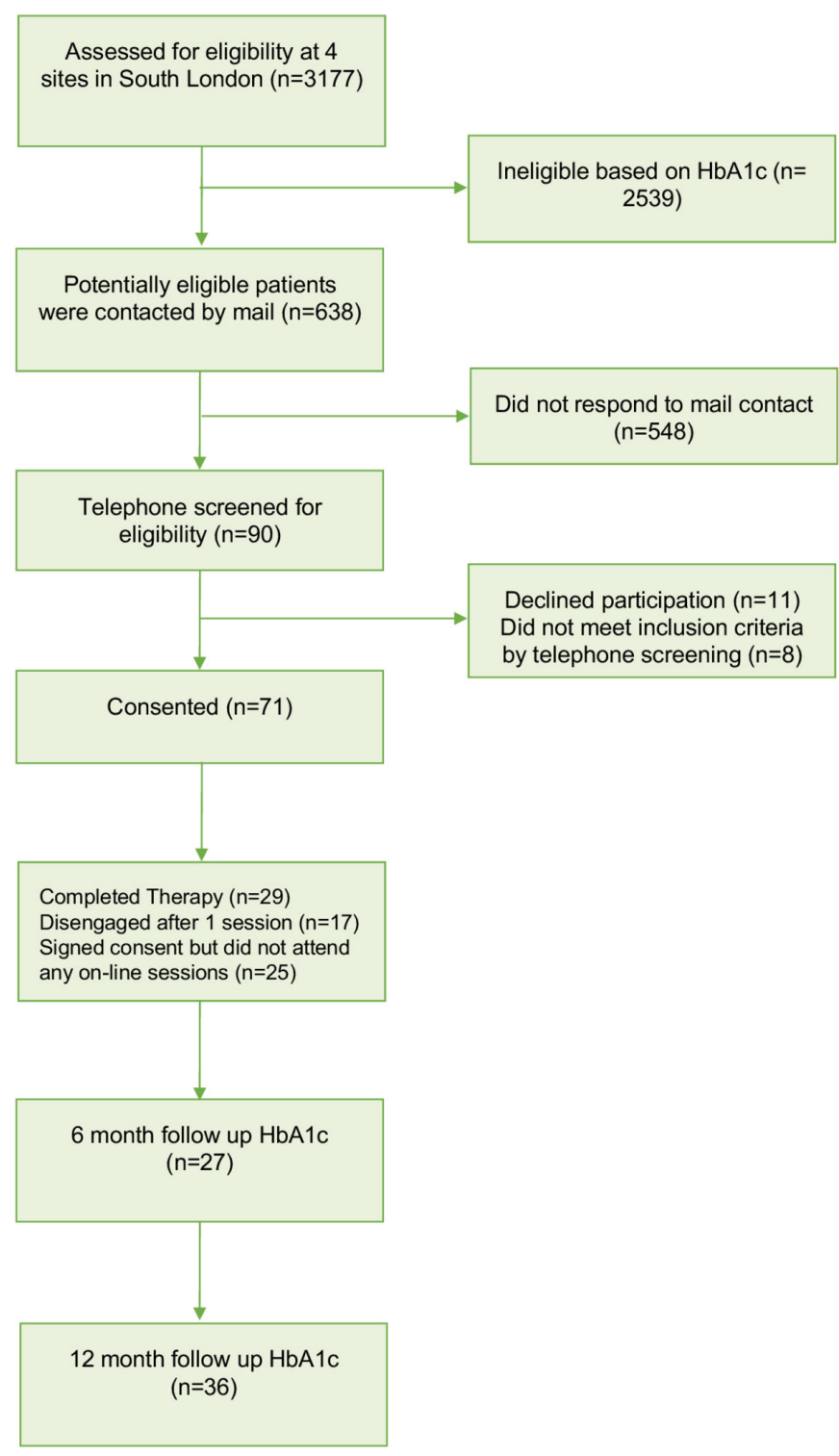

Figure 1 Consort flow diagram showing recruitment and attrition. 
Table 1 Comparison of baseline characteristics by those with and without 12-month HbA1c data

\begin{tabular}{|c|c|c|c|}
\hline & $\begin{array}{l}\text { Total at baseline } \\
(\mathrm{n}=71)\end{array}$ & $\begin{array}{l}\text { Those with HbA1c data } \\
\text { at } 12 \text { months }(n=36)\end{array}$ & $\begin{array}{l}\text { Those with no HbA1c } \\
\text { data at } 12 \text { months }(n=35)\end{array}$ \\
\hline Age, mean (SD) & $38.1(13.1)$ & $39(12.5)$ & $37.3(13.9)$ \\
\hline \multicolumn{4}{|l|}{ Gender, n (\%) } \\
\hline Male & $17(23.9)$ & $8(22.2)$ & $9(25.7)$ \\
\hline Female & $54(76.1)$ & $28(77.8)$ & $26(74.3)$ \\
\hline \multicolumn{4}{|l|}{ Ethnicity, n (\%) } \\
\hline White & $63(92.6)$ & $35(94.4)$ & $28(87.5)$ \\
\hline Black, Asian, minority ethnic & $5(7.4)$ & $1(2.8)$ & $4(12.5)$ \\
\hline \multicolumn{4}{|l|}{ Education, $\mathrm{n}(\%)$} \\
\hline No examinations completed & $2(3.4)$ & $1(3.8)$ & $1(3.1)$ \\
\hline GSCEs/O-levels or equivalent & $13(22.4)$ & $6(23.1)$ & $7(21.9)$ \\
\hline A-levels or equivalent & $13(22.4)$ & $8(30.8)$ & $5(15.6)$ \\
\hline University degree or higher & $30(51.8)$ & $11(42.3)$ & $19(59.4)$ \\
\hline \multicolumn{4}{|l|}{ Employment status, $\mathrm{n}(\%)$} \\
\hline Employed full time & $37(63.8)$ & $19(70.4)$ & $18(58.1)$ \\
\hline Employed part time & $7(12.1)$ & $2(7.4)$ & $5(16.1)$ \\
\hline Sick leave, unemployed, homemaker & $9(15.5)$ & $5(18.5)$ & $4(12.9)$ \\
\hline Retired & $2(3.4)$ & $1(3.7)$ & $1(3.2)$ \\
\hline Student & $3(5.2)$ & $0(0)$ & $3(9.7)$ \\
\hline Smoker, $\mathrm{n}(\%)$ & $14(26.4)$ & $7(29.2)$ & $7(24.1)$ \\
\hline Duration of diabetes in years, mean (SD) & $18.3(10.3)$ & $16.6(10.2)$ & $20.2(10.2)$ \\
\hline Baseline $\mathrm{HbA} 1 \mathrm{c}$ in mmol/mol, mean (SD) & $84.6(17.8)$ & $83.3(15.9)$ & $85(17.3)$ \\
\hline Depressive symptoms at baseline (PHQ-9 score), mean (SD) & $4.6(3.3)$ & $5.4(4.1)$ & $3.5(3.5)$ \\
\hline Anxiety symptoms at baseline (GAD-7 score), mean (SD) & $4(3.9)$ & $5.3(5.3)$ & $5.3(5.3)$ \\
\hline Diabetes distress at baseline (DDS score), mean (SD) & $48.2(10.2)$ & $44.6(15.8)$ & $44.9(15.7)$ \\
\hline At least mild symptoms $(\geq 5)$ on PHQ-9 or GAD-7, $n(\%)$ & $47(66.2)$ & $26(72.2)$ & $21(60)$ \\
\hline
\end{tabular}

DDS, Diabetes Distress Scale; GAD-7, Generalised Anxiety Disorder 7-item scale (a measure of symptoms of anxiety); GSCE, General Certificate of Secondary Education; PHQ-9, Patient Health Questionnaire-9 (a measure of depressive symptoms).

HbA1c was 84.6 (17.8) $\mathrm{mmol} / \mathrm{mol}$. While mean levels of depressive and anxiety symptoms were below diagnostic thresholds for their respective disorders, there were significant levels of diabetes-related distress (table 1).

Of the 71 people who consented, 25 (35.2\%) did not attend their first online session; 17 (24\%) attended either 1 or 2 sessions and $29(40.9 \%)$ completed all 10 sessions. Baseline data were collected on all individuals who consented to the study. Six-month and 12-month HbA1c data were collected for $27(38 \%)$ and $36(51 \%)$ patients, respectively. There were no significant differences in baseline demographic or clinical variables between those with and without 12-month $\mathrm{HbA1c}$ results (table 1, test statistics not shown). We observed a significant mean reduction in $\mathrm{HbA1c}$ from baseline to 12 months (table 2) of $6.2(2.5) \mathrm{mmol} / \mathrm{mol}(\mathrm{p}=0.038)$.

Twenty-two patients completed the psychological measures at 12 months. There was a non-significant mean reduction in scores for the PHQ-9 (mean difference-2.2 (1.0), $\mathrm{p}=0.129$ ), the GAD-7, (mean difference-4.3 (2.3), $(\mathrm{p}=0.031))$ and in the DDS (mean difference-3.4 (1.7), $\mathrm{p}=0.37)$. There were no patients who scored $\geq 10$ on the PHQ-9; therefore, we used the $\geq 5$ cut-off for mild symptoms of anxiety. When we stratified patients into those with and without depressive or anxiety symptoms using cut-offs of PHQ-9 $\geq 5$ and/or GAD-7 score $\geq 10$,

Table 2 Changes in HbA1c and psychological measures over 12-month follow-up, in patients for whom there were follow-up data available $(n=36)$

\begin{tabular}{|c|c|c|c|c|}
\hline Measure & Baseline & 12 months & $\begin{array}{l}\text { Net change: baseline to } 12 \\
\text { months }\end{array}$ & $P$ value (paired t-test) \\
\hline $\mathrm{HbA} 1 \mathrm{c}, \mathrm{mmol} / \mathrm{mol}$, mean (SD) $(\mathrm{n}=36)$ & $84.6(17.8)$ & $78.4(15.3)$ & -6.2 & 0.038 \\
\hline PHQ-9 score, mean (SD) $(n=22)$ & $4.6(3.3)$ & $3.4(2.2)$ & -2.2 & 0.14 \\
\hline GAD-7 score, mean (SD) $(n=22)$ & $4(3.9)$ & $1.0(1.6)$ & -3.0 & 0.037 \\
\hline DDS score, mean (SD) $(n=22)$ & $48.2(10.2)$ & $37.8(20.4)$ & 10.4 & 0.225 \\
\hline
\end{tabular}

DDS, Diabetes Distress Scale; GAD-7, Generalised Anxiety Disorder 7-item scale (a measure of symptoms of anxiety); PHQ-9, Patient Health Questionnaire-9. 
Table 3 Changes in HbA1c and psychological measures over 12-month follow-up in participants with PHQ-9 $\geq 5$ or GAD-7 $\geq 10$ (ie, at least mild symptoms of depression or anxiety) $(n=22)$

\begin{tabular}{|c|c|c|c|c|}
\hline Measure & Baseline & 12 months & $\begin{array}{l}\text { Net change: } \\
\text { baseline to } 12 \text { months }\end{array}$ & $P$ value \\
\hline \multicolumn{5}{|c|}{ Those with at least mild symptoms (PHQ-9 $\geq 5$ or GAD- $7 \geq 10$ ) } \\
\hline Baseline $\mathrm{HbA} 1 \mathrm{c}, \mathrm{mmol} / \mathrm{mol}$, mean (SD) & $82.1(17.7)$ & $75.5(13.9)$ & -6.6 & 0.07 \\
\hline Baseline PHQ-9 score, mean (SD) & $6(2.5)$ & $4.3(1.5)$ & -1.7 & 0.129 \\
\hline Baseline GAD-7 score, mean (SD) & $5.8(3.8)$ & $1.5(1.7)$ & -4.3 & 0.031 \\
\hline Baseline DDS score, mean (SD) & $48.8(11.3)$ & $45.4(9.6)$ & -3.4 & 0.37 \\
\hline Baseline $\mathrm{HbA} 1 \mathrm{c}, \mathrm{mmol} / \mathrm{mol}$, mean (SD) & $95.4(15.5)$ & $91.1(16.1)$ & -4.3 & 0.18 \\
\hline Baseline PHQ-9 score, mean (SD) & $1(1.2)$ & $3.9(5.2)$ & +2.9 & 0.028 \\
\hline Baseline GAD-7 score, mean (SD) & $0.5(0.7)$ & $0(0)$ & -4.3 & 0.114 \\
\hline Baseline DDS score, mean (SD) & $48.8(11.3)$ & $45.4(9.6)$ & -3.4 & 0.5 \\
\hline
\end{tabular}

Values in bold are those with a statistically significant $(p<0.05)$ change from baseline to 12 months.

DDS, Diabetes Distress Scale; GAD-7, Generalised Anxiety Disorder 7-item scale (a measure of symptoms of anxiety); PHQ-9, Patient Health Questionnaire (a measure of depressive symptoms).

respectively, to include those with at least mild symptoms of depression or anxiety $(\mathrm{n}=22)$, there was a slightly greater improvement in glycemic control (table 3) and greater decrease in depressive and anxiety symptoms compared with those with subthreshold or no depressive or anxiety symptoms. Those with depressive or anxiety scores below these cut-offs at baseline showed a statistically significant mean increase in depressive symptoms, although the increased level was low (3.9), below the threshold for mild symptoms of depression and therefore unlikely to be of clinical significance. There were no significant differences in the change in glycemic control over 12 months stratified by the recruitment sites (results not shown).

When we stratified patients into those with and without depressive or anxiety symptoms using cut-offs of PHQ-9 $\geq 5$ and/or GAD-7 score $\geq 5$ to include those with all mild symptoms of depression or anxiety $(\mathrm{n}=27)$, there was a significant improvement in glycemic control (-5.3 $\mathrm{mmol} / \mathrm{mol} ; \mathrm{p}=0.038)$. There was a significant decrease in depressive symptoms $(-3.3 ; \mathrm{p}=0.037)$. The trend decreases in GAD and DDS, although clinically significant, were not statistically significant. There were no follow-up data for any participants who scored $<5$ on both PHQ-9 and GAD-7 at baseline.

We invited patients to give us verbal feedback and invited them to a feedback session following the end of the therapy. Patients described DOT as a "positive experience" and that the convenience was an important aspect of the therapy. They agreed that it was a flexible, accessible mode of therapy and it was useful to have the transcript available between sessions. They reported that the therapist was approachable and empathic, despite being unable to see them. One patient who had had previous face-to-face therapy reported that it was easier to focus on conveying their thoughts and feelings, and to get their points across in the online setting. Another patient reported that the intervention was welcome but that it made them realize they needed even more help.

\section{DISCUSSION}

We conducted a feasibility study of online diabetesfocused CBT intervention for people with type 1 diabetes. The key findings were that the eligible population (those with persistent hyperglycemia defined as HbA1c $\geq 69$ $\mathrm{mmol} / \mathrm{mol}$ ) was about $20 \%$ of all people with type 1 diabetes. Of those who replied to our invitation, we had a high participation rate. We acknowledge that many patients did not reply to our invitation. We do not know all the reasons for this, which may include lack of access to internet and devices (which may reduce the accessibility of this intervention), did not perceive that they may need psychological support, not willing to give the time commitment (which may also have been a barrier) and incorrect contact details. The target population is a particularly vulnerable group of patients with high levels of diabetes distress suggesting significant suffering, for whom conventional diabetes care pathways have not been effective in improving their glycemic control. This may reflect stigma and lack of knowledge about the impact of mental health on diabetes self-care and factors related to digital literacy. Around $65 \%$ of the patients participated in at least one session of therapy and $41 \%$ completed all 10 sessions during the study period, suggesting reasonable fidelity. This is in keeping with uptake rates for brief psychological interventions for depression and specifically in diabetes. ${ }^{30}{ }^{31}$ This may reflect stigma and lack of knowledge about the impact of mental health on diabetes self-care and factors related to digital literacy. ${ }^{32}$

Preliminary estimates of effectiveness suggest a small but clinically significant reduction in HbAlc and improvement in psychological functioning. The sample did not have high levels of depressive or anxiety symptoms, but they did have high levels of diabetes distress. The attrition rate for follow-up of HbAlc at 12 months was around $50 \%$ which may be partly due to the study relying on routine $\mathrm{HbA1c}$ data collection in a population that struggles with self-care, which includes attending appointments. Paradoxically, DOT was developed to 
make psychological interventions more accessible to those living in more remote areas and to reduce travel costs in this group who have long distances to travel for hospital appointments. This strategy of collecting routine data may need to be reconsidered in a full-scale RCT.

This improvement in glycemic control was comparable with other studies of psychological treatments to support diabetes self-management. ${ }^{33}$ An RCT of face-to-face CBT conducted by the same investigators observed a reduction in HbAlc of $5.5 \mathrm{mmol} / \mathrm{mol} .{ }^{13}$ Our findings are comparable with those of a feasibility RCT for people with type 1 and type 2 diabetes comparing an online CBT program with therapist support provided by phone and email versus treatment as usual for depression, ${ }^{21}$ although the difference was that our inclusion criterion was suboptimal glycemic control, whereas in that study it was depressive symptoms and they included type 2 diabetes. In our study, those patients who had symptoms of depression or anxiety at baseline were the subgroup with significant improvements in glycemic control. Although this is an underpowered observation, it does suggest that people with suboptimal diabetes control in addition to psychological distress may be a target population for future diabetes-focused psychological interventions.

The strengths of this feasibility study include recruitment of patients from teaching and non-teaching hospitals serving a diverse socioeconomic, ethnic and geographical populations. We were able to identify a sufficient number of high-risk patients using routine hospital medical records, despite the absence of standardized type 1 diabetes registers. This study was the first that we are aware of to test online real-time text-based diabetes CBT integrated with type 1 diabetes care.

The limitations were that we did not measure alcohol or substance abuse, personality traits, illness perceptions, disordered eating or self-efficacy. We did this to minimize patient burden while collecting data remotely but acknowledge that these may have been important predictors of outcome. Some patients may have had higher levels of psychiatric morbidity for whom text-based CBT by a DSN may not be suitable and may explain why some patients did not respond to the invitation or the intervention, as they may have needed more formal psychiatric care, consistent with patient feedback.

The uptake of online therapy was comparable with other studies, but there is scope for increasing this, especially in considering that around $50 \%$ of those recruited did not participate in therapy. ${ }^{34}$ As this was a virtual intervention, it was difficult to make contact with patients once they had dropped out; therefore, we were unable to ask about their reasons and also could not collect psychological outcomes. However, we were able to collect glycemic control outcomes from routine medical records. The aim of the DSN training was to minimize demands on nurse time while developing basic CBT skills. We did not measure the level of competencies in CBT. This is because this is a significant exercise in terms of costs and time which was outside the scope of this feasibility study. It requires qualified CBT therapists trained in conducting CBT rating scales and assessment of inter-rater reliability to assess reporting biases. Based on previous studies, it is likely they had beginner-level proficiency and it is possible that higher levels of proficiency may have delivered better outcomes. ${ }^{35}$ There may have been dilution of CBT skills because the nurse may also have had to deliver diabetes education and nursing advice. However, formal training in generic CBT typically requires 1 year of full-time study which is prohibitive for the majority of diabetes professionals. This study demonstrates that while it is feasible to train DSN in basic CBT, whether intensification of CBT training may improve the effectiveness of the intervention remains to be studied by using appropriate competency measures.

\section{CONCLUSIONS}

The improvements in glycemic control reported here was promising, especially when compared with previous psychological interventions designed at improving diabetes management in patients using psychological therapies. This suggests potential for both a diabetesfocused CBT and real-time text-based treatment modality, the efficacy of which will need further evaluation in RCT studies.

\section{Author affiliations}

${ }^{1}$ Psychiatry, University College Dublin, Dublin, Ireland

${ }^{2}$ Psychiatry, Mater Misericordiae University Hospital, Dublin, Ireland

${ }^{3}$ Department of Internal Medicine VI/Psychosomatic Medicine and Psychotherapy, University Hospital Tubingen, Tubingen, Baden-Württemberg, Germany

${ }^{4}$ Psychiatry, UCL, London, UK

${ }^{5}$ Diabetes, King's College Hospital NHS Foundation Trust, London, UK

${ }^{6}$ Mental Health Research Unit, The University of Sheffield, Sheffield, UK

${ }^{7}$ Institute of Psychiatry, Psychology \& Neuroscience, King's College London, London, UK

Acknowledgements The authors would like to acknowledge the assistance of Ann Hayes of IESO Digital Health, our technological partners. We thank the participating Diabetes Centres and the people living with diabetes who were involved, and the five diabetes specialist nurses who volunteered their time to attend training and deliver the interventions.

Contributors AMD, KI, SW and AH-W planned the intervention. AH-W, Kl and AMD wrote the treatment manual. AMD and $\mathrm{AH}-\mathrm{W}$ trained and supervised the nursetherapists. JB was involved in the delivery of the intervention. AR collected and managed the data. Data analysis was conducted by AR and AMD. This report was drafted by AMD, and all authors contributed to the writing and editing of the final paper.

Funding This study was funded by SBRI for the development of the technology (2013-10/62/03). Funding of the delivery of the intervention was obtained from the Health Foundation via their SHINE award (7309 CRM 1407).

Competing interests None declared.

Patient consent for publication Not required.

Ethics approval This study received ethical approval from the NRES Committee London (Bromley) reference no 14-L0-0424.

Provenance and peer review Not commissioned; externally peer reviewed.

Data availability statement Data are available on reasonable request.

Open access This is an open access article distributed in accordance with the Creative Commons Attribution Non Commercial (CC BY-NC 4.0) license, which permits others to distribute, remix, adapt, build upon this work non-commercially, and license their derivative works on different terms, provided the original work is 
properly cited, appropriate credit is given, any changes made indicated, and the use is non-commercial. See: http://creativecommons.org/licenses/by-nc/4.0/.

ORCID iD

Anne M Doherty http://orcid.org/0000-0002-6995-5361

\section{REFERENCES}

1 NICE. Type 1 diabetes in adults: diagnosis and management (2015). NICE guideline NG17 2016.

2 The Diabetes Control and Complications Trial/Epidemiology of Diabetes Interventions and Complications (DCCT/EDIC) Study Research Group. Intensive diabetes treatment and cardiovascular disease in patients with type 1 diabetes. $N$ Engl $\mathrm{J} \mathrm{Med}$ 2005;353:2643-53.

3 McIntyre HD. DAFNE (Dose Adjustment for Normal Eating): structured education in insulin replacement therapy for type 1 diabetes. Med J Aust 2006;184:317-8.

4 Pollard DJ, Brennan A, Dixon S, et al. Cost-effectiveness of insulin pumps compared with multiple daily injections both provided with structured education for adults with type 1 diabetes: a health economic analysis of the Relative Effectiveness of Pumps over Structured Education (REPOSE) randomised controlled trial. BMJ Open 2018;8:e016766.

5 Stahl-Pehe A, Glaubitz L, Bächle C, et al. Diabetes distress in young adults with early-onset type 1 diabetes and its prospective relationship with $\mathrm{HbA}_{1 \mathrm{c}}$ and health status. Diabet Med 2019;36:836-46.

6 Fisher L, Gonzalez JS, Polonsky WH. The confusing tale of depression and distress in patients with diabetes: a call for greater clarity and precision. Diabet Med 2014;31:764-72.

7 Johnson B, Eiser C, Young V, et al. Prevalence of depression among young people with type 1 diabetes: a systematic review. Diabet Med 2013;30:199-208.

8 Nuccitelli C, Valentini A, Caletti MT, et al. Sense of coherence, selfesteem, and health locus of control in subjects with type 1 diabetes mellitus with/without satisfactory metabolic control. J Endocrinol Invest 2018;41:307-14.

9 Hagger V, Hendrieckx C, Sturt J, et al. Diabetes distress among adolescents with type 1 diabetes: a systematic review. Curr Diab Rep 2016;16:1-14.

10 Brown JB, Valliere Y, McLachlan C, et al. Beyond the sick role: the many roles of adults with type 1 and type 2 diabetes in the management of hypoglycemia-The InHypo-DM Study, Canada. Can J Diabetes 2020;44:657-62.

11 Ismail K, Stewart K, Ridge K, et al. A pilot study of an integrated mental health, social and medical model for diabetes care in an inner-city setting: Three Dimensions for Diabetes (3DFD). Diabet Med 2020;37:1658-68

12 Winkley K, Ismail K, Landau S, et al. Psychological interventions to improve glycaemic control in patients with type 1 diabetes: systematic review and meta-analysis of randomised controlled trials. BMJ 2006;333:65.

13 Ismail K, Thomas SM, Maissi E, et al. Motivational enhancement therapy with and without cognitive behavior therapy to treat type 1 diabetes: a randomized trial. Ann Intern Med 2008;149:708-19.

14 Maissi E, Ridge K, Treasure J, et al. Nurse-led psychological interventions to improve diabetes control: assessing competencies. Patient Educ Couns 2011:84:e37-43.

15 Patel A, Maissi E, Chang $\mathrm{H}-\mathrm{C}$, et al. Motivational enhancement therapy with and without cognitive behaviour therapy for type diabetes: economic evaluation from a randomized controlled trial. Diabet Med 2011:28:470-9.

16 Ridge K, Bartlett J, Cheah Y, et al. Do the effects of psychological treatments on improving glycemic control in type 1 diabetes persist over time? A long-term follow-up of a randomized controlled trial. Psychosom Med 2012;74:319-23.

17 Faruque LI, Wiebe N, Ehteshami-Afshar A, et al. Effect of telemedicine on glycated hemoglobin in diabetes: a systematic review and meta-analysis of randomized trials. CMAJ 2017; 189:E341-64.

18 Forbes A, While A, Griffiths P, et al. Organizing and delivering diabetes education and self-care support: findings of scoping project. J Health Serv Res Policy 2011;16:42-9.

19 Ozcan S, Rogers H, Choudhary P, et al. Redesigning an intensive insulin service for patients with type 1 diabetes: a patient consultation exercise. Patient Prefer Adherence 2013;7:471-80.

20 Kessler D, Lewis G, Kaur S, et al. Therapist-delivered Internet psychotherapy for depression in primary care: a randomised controlled trial. Lancet 2009;374:628-34.

21 Newby J, Robins L, Wilhelm K, et al. Web-based cognitive behavior therapy for depression in people with diabetes mellitus: a randomized controlled trial. J Med Internet Res 2017;19:e157.

22 Office for National Statistics. Regional ethnic diversity. London, 2018. Available: https://www.ethnicity-facts-figures.service.gov. uk/uk-population-by-ethnicity/national-and-regional-populations/ regional-ethnic-diversity/latest [Accessed 4 Jun 2019]

23 Kroenke K, Spitzer RL, Williams JB. The PHQ-9: validity of a brief depression severity measure. J Gen Intern Med 2001;16:606-1.

24 Spitzer RL, Kroenke K, Williams JBW, et al. A brief measure for assessing generalized anxiety disorder: the GAD-7. Arch Intern Med 2006;166:1092-7.

25 Swinson RP. The GAD-7 scale was accurate for diagnosing generalised anxiety disorder. Evid Based Med 2006;11:184

26 Plummer F, Manea L, Trepel D, et al. Screening for anxiety disorders with the GAD-7 and GAD-2: a systematic review and diagnostic metaanalysis. Gen Hosp Psychiatry 2016;39:24-31.

27 Ahn J-K, Kim Y, Choi K-H. The psychometric properties and clinica utility of the Korean version of GAD-7 and GAD-2. Front Psychiatry 2019;10:127.

28 Polonsky WH, Fisher L, Earles J. Assessing psychosocial stress in diabetes. Diabetes Care 2005;28:626-31.

29 Graue M, Haugstvedt A, Wentzel-Larsen T, et al. Diabetes-related emotional distress in adults: reliability and validity of the Norwegian versions of the Problem Areas in Diabetes Scale (PAID) and the Diabetes Distress Scale (DDS). Int J Nurs Stud 2012;49:174-82.

30 Department of Health. IAPT three-year report: the first million patients. London: DoH, 2012.

31 SPSS: IBM Corp. IBM SPSS statistics for Windows, version 21.0. Armonk, NY: IBM Corp, 2012.

32 Esbitt SA, Batchelder AW, Tanenbaum ML, et al. "Knowing that you're not the only one": perspectives on group-based cognitivebehavioral therapy for adherence and depression (CBT-AD) in adults with type 1 diabetes. Cogn Behav Pract 2015;22:393-406.

33 Winkley K, Upsher R, Stahl D, et al. Systematic review and meta-analysis of randomized controlled trials of psychological interventions to improve glycaemic control in children and adults with type 1 diabetes. Diabet Med 2020;37:735-46.

34 van Ballegooijen W, Cuijpers P, van Straten A, et al. Adherence to Internet-based and face-to-face cognitive behavioural therapy for depression: a meta-analysis. PLoS One 2014;9:e100674.

35 Ismail K, Winkley K, de Zoysa N, et al. Nurse-led psychological intervention for type 2 diabetes: a cluster randomised controlled trial (Diabetes-6 study) in primary care. Br J Gen Pract 2018;68:e531-40. 